\title{
Teatro social y femenino
}

Una mirada a través de la dramaturgia de Carmen Pombero

\section{Eva Romero-Molina}

\section{OpenEdition}

\section{Journals}

Edición electrónica

URL: https://journals.openedition.org/cher/1095

DOI: 10.4000/cher.1095

ISSN: 2803-5992

Editor

Presses universitaires de Strasbourg

\section{Edición impresa}

Fecha de publicación: 11 julio 2019

Paginación: 77-87

ISBN: 979-10-344-0046-1

ISSN: 1968-035X

Referencia electrónica

Eva Romero-Molina, «Teatro social y femenino», reCHERches [En línea], 22 | 2019, Publicado el 04 octubre 2021, consultado el 17 noviembre 2021. URL: http://journals.openedition.org/cher/1095; DOI: https://doi.org/10.4000/cher.1095 


\title{
Teatro social y femenino \\ Una mirada a través de la dramaturgia de Carmen Pombero
}

\author{
EVA ROMERO-MOLINA ${ }^{1}$
}

$\mathrm{H}$ ablar de teatro social sigue siendo hoy día problemático si tenemos en cuenta que lo social, tradicionalmente, se ha opuesto a lo individual en un afán por obtener precisamente una lectura ideológica del texto dramático, confundiéndose la ideología - un teatro ideológico-político- con la inscripción social en una obra. Como hace la socio-crítica debemos reflexionar -para no caer en el error de enfrentar lo social al individuo- en esta inscripción o en la confrontación dialéctica entre lo individual y la sociedad. Por ello, plantearé cómo lo social se inscribe en la ficcionalidad, en la estructura y en la especificidad de la dramaturgia de Carmen Pombero.

En el teatro se encuentra un campo de abono para el estudio social, pues, en él encontramos, como describe Patrice Pavis, unos hombres y mujeres que juegan a representar a otros hombres y mujeres, mostrándosenos cómo estos se comportan en sociedad (Pavis 1998: 43).

El texto dramático, por naturaleza, va a utilizar el lenguaje como un discurso interpersonal capaz de crear el desequilibrio y el conflicto necesarios para mostrar a unos individuos en un estado de desconformidad en el que tendrán que optar por la modificación de su situación o la asunción de la misma. Este sistema dramático plantea, en definitiva, a través del diálogo de los personajes, distintas fuerzas sociales que pretenderán imponerse a otras.

Para el acercamiento a la dramaturgia de Carmen Pombero me he aproximado a diversos textos, desde obras mayores a teatro breve y mínimo; pero, finalmente, me he decantado por dos textos significativos de su producción. Por un lado, Cuando regreses a Nueva York ${ }^{2}$ (Pombero 2004) y por otro, Amina ${ }^{3}$ (Pombero

1 Eva Romero-Molina, Departamento de Ciencias Teatrales - Escuela Superior de Arte Dramático de Málaga.

2 Obra ganadora en el "V Premio José Martín Recuerda" en el año 2003.

3 Obra ganadora en el "IV Premio de teatro breve dramaturgo José Moreno Arenas" en el año 2012. 
2012), por reflejar dos ambientes sociales y contextuales distintos y en los que a través de estos conoceremos a unos personajes que intentarán desenvolverse en los mismos. Así mismo, estos dos textos, pertenecientes a culturas distintas nos permiten realizar una comparativa desde la inscripción social de la mujer ya que ambos nos muestran cómo estas tradicionalmente han sido relegadas en determinas funciones sociales en detrimento de su libertad. Estos textos, nos muestran cómo a través de las fuerzas sociales en conflicto, la fuerza social creada por el hombre se impondrá a la de la mujer.

Contextualizar el papel de la mujer en nuestra sociedad occidental nos obliga a trasladarnos, ni más ni menos, que al siglo XVIII cuando algunos hombres creyeron oportuno que la mujer comenzara a acompañarlos a los salones donde acudían los intelectuales; es por ello, por lo que se empezó a desear una mujer más culta e intelectual: las Salonières. Claro está, que esto no fue mayoritario; las mujeres formadas no dejaban de ser una pequeña élite dentro de la burguesía, pues la mayor parte de las mujeres de una clase superior se dedicaban a placeres más superficiales.

Pero será Jean Jacques Rousseau quien criticará esa forma de vida baladí por sustentar la desigualdad social, devolviendo la mujer al hogar. Rousseau exponía que los placeres de la vida en la ciudad eran malos para la sociedad y que aún era peor para la mujer, pues, se interponía en el bienestar moral del núcleo societal. En consecuencia, el papel de la mujer como madre era, a la vez, importante y por su puesto, limitado. Establecer moral sobre su familia, educar y cuidar a los hijos formaban su cometido social.

Cuando la burguesía se consolida durante el siglo XIX estos valores tradicionales serán reforzados y la diferencia entre sexos aumentará considerablemente. Hombres y mujeres se presentan como seres opuestos y la mujer supeditada al hombre. La oposición establecida entre ambos sexos mostrará a la mujer como emocional y al hombre como racional estableciéndose unos binomios innumerables; ella delicada, él fuerte; ella abnegada frente a él autoritario, y así un largo etc. El espacio público estaba reservado al hombre, mientras que el de la mujer se restringía al doméstico.

Este legado ha continuado imperante durante el siglo XX y todavía hoy cuesta desprenderse de determinados clichés impuestos a la mujer. A través de los de los textos dramáticos seleccionados de C. Pombero intentaré explorar cómo las huellas de este modelo familiar y moral todavía siguen presentes en la sociedad actual.

Las dos obras propuestas plantean estructuras distintas por focalizar diferentes decisiones de sus protagonistas femeninas en situaciones claves. Esto nos lleva a diferenciar entre las protagonistas activas de Cuando regreses a Nueva york, que darán un giro a su vida, y las pasivas de Amina que incapaces de soportar el dolor acabarán sucumbiendo, sin atisbo de lucha, debido a un determinismo impuesto a nivel político, social, y cultural.

De este modo, Cuando regreses a Nueva York, parte de un entorno que nos remite a una familia media española que cohabita con unas normas sociales 
asignadas sin que hasta el momento hayan sido conscientes de su propia infelicidad. Amina, sin embargo, nos queda más lejos, desarrollándose la acción en Marruecos y en la que se nos muestra la falta de castigo ante las violaciones femeninas.

Ambos textos parten de un contexto social donde la figura de la mujer ha sido sometida a una sociedad patriarcal para beneficio del género masculino y detrimento del femenino. En ambos, el gran beneficiado es el hombre y, también en ambos, la figura de la mujer es la que renuncia, la que se sacrifica, la se ve obligada a consentir por el desequilibrio imperante entre hombre y mujer y la que tiene asumido un papel que da por válido. Así vemos cual es la reacción de Isabel ante el divorcio de sus padres:

IsABEL. No me voy a tragar que mis padres, mi modelo de familia y de pareja, se deshaga de buenas a primera por culpa de una enfermedad. Ella debería quedarse a su lado. ¿Ves cómo madre siempre ha ido a lo suyo? En el momento más difícil en la vida de papá, le abandona. (Pombero 2004: 57)

Pero para adentrarnos más en los elementos sociales y en el papel de la mujer dentro de estos contextos tan distintos me detendré en la primera obra mencionada. Este entorno, refiere nuestra sociedad actual, por ello expondré de manera sumaria la materia fabular con la que C. Pombero intenta acercarnos a una realidad cultural y social.

Paco marcha a Nueva York donde, por fin, vive su homosexualidad libremente, pero el hecho de tener que volver tras un fracaso sentimental a España le hará ocultar de nuevo su verdadera identidad sexual. Su hermana, por otra parte, se casa con Jaime, quien regenta una ferretería. La negativa de Jaime a visitar a Paco en Nueva York, por un lado, y la de tener hijos, por otro, harán de Isabel una mujer desdichada. El detonante de la obra será la situación límite a la que la familia será llevada por la enfermedad del padre de ambos, José. Poco a poco, se nos irá mostrando la enfermedad que sufre, Alzheimer, y como esta a través de sus delirios nos revelará la infidelidad a María, su mujer, la muerte de Luisa -hija del matrimonio- cuando era bebé, y las consecuencias de estos dos grandes hechos en María, una mujer educada para cuidar marido e hijos.

El divorcio que se producirá entre el matrimonio a una edad tan avanza hace que sus propios hijos tomen conciencia de la brevedad de la vida y, de este modo, Paco volverá a marchar a Nueva York e Isabel emprenderá una nueva vida lejos de su marido. Algo que ya se prefigura en el primer interludio cuando Isabel lee una de las cartas que su hermano escribió desde Nueva York y que ella todavía conserva:

IsABEL. [...] Hoy, he tenido otra oportunidad, porque esta mañana me lamentaba por dormir mientras nevaba [...] Quizás, siempre hay una segunda oportunidad para hacer y disfrutar de aquello que deseamos, Isabel, y no sabemos apreciarla o simplemente, la dejamos escapar... (Pombero 2004: 37)

Sin duda, estos personajes que anteriormente he denominado como activos están condicionados culturalmente por el patriarcado; aun así, pueden modificar 
sus vidas porque socialmente se les permite emprender ese viaje. La rebelión de su madre será para ellos la luz a hacia su nueva vida, al igual que su silencio mantenido durante años supuso para Paco e Isabel la aceptación de dicho patriarcado.

Que el determinismo está presente en todos los personajes de estas dos obras e incluso en la mayoría de la producción de Carmen Pombero, es señal de su compromiso por un teatro social que intenta dialogar con un determinismo impuesto en los sistemas sociales en todos sus niveles y con un determinismo individual propiciado por el contexto ambiental o educacional.

De este modo, Cuando regreses a Nueva york plantea ese diálogo interno entre "el Paco" de Nueva York y "el Paco" ayudante en la ferretería de su cuñado; entre "la Isabel" condescendiente con los deseos de Jaime y "la Isabel" que ya no quiere lo que no desea.

La estructura que plantea la obra apoya el contenido de la misma y es que se privilegian escenas que permiten la introspección de los personajes, como es el caso del primer interludio donde se simultanean el recuerdo como motivo esperanzador y también como dolor a través de dos espacio-temporalidades simultáneas. De esta forma, podemos ver a Isabel leyendo una de las cartas enviadas desde Nueva York por su hermano Paco, que como la propia autora expone en la acotación: "Parece que haya rejuvenecido...pero solo se trata de la impresión que deja sobre ella la lectura de las cartas que Paco le escribía desde Nueva York" (Pombero 2004: 34). Sin embargo, el dolor y la tristeza corren de parte de María que, al ojear un álbum fotográfico, hallará la foto de su hija Luisa. El dolor se apodera de ella, y volverá a ser Paco el que mitigue su sufrimiento, ya que al igual que Isabel, María encuentra una nueva foto, esta vez de su hijo, tomada en Nueva York.

Nueva York es el lugar donde los sueños se cumplen, es el lugar idealizado por todos los personajes, menos por Jaime. Estos dos recuerdos encontrados entre sí provocarán un dilema en María que no sabrá qué lugar debe ocupar la foto de Luisa ni la foto de Paco, o lo que es lo mismo, que lugar debe ocupar el dolor frente a la felicidad:

(MARÍA se levanta de la butaca, con la fotografía en la mano y busca en el cajón de una cómoda. Saca un viejo marco y coloca la foto en él).

(MARÍA se levanta y coge el marco que había dejado sobre la cómoda con la foto de su hija LUISA. La quita, para colocar en su lugar la de Paco) (Pombero 2004: 35-36).

No obstante, el interludio acabará con la lectura del final de la carta, que refleja el carácter optimista de Paco cuando reza: “...siempre hay una segunda oportunidad para hacer y disfrutar de aquello que deseamos...” (Pombero 2004: 37). El uso de monólogos y soliloquios, junto con este interludio, se presentan como herramienta para que conozcamos un pasado errado de los personajes del que progresivamente irán tomando conciencia. Probablemente, Paco es el único personaje que desde el principio es consciente de su propia realidad y 
el que precisamente ha asumido su derrota: sus sueños han sucumbido ante el peso aplastante de tener que regresar de Nueva York y ocultar de nuevo su homosexualidad y así se nos muestra en el soliloquio de la Escena I: "Esa ciudad... Prometí que nunca podría conmigo. Que sobreviviría a su dureza... Me equivoque, tal vez..." (Pombero 2004: 17).

Este conocimiento hace a Paco menos infeliz, excepto cuando tiene que enfrentarse con su cuñado Jaime, que siempre le recuerda su fracaso en Nueva York:

JAIME. Ese es tu problema, cuñado. No sabes aprovechar las oportunidades. Seguro que en los quince años que estuviste en Estados Unidos podrías haber hecho algo mejor que trabajar de camarero en esos restaurantes gallegos del West Side [...] Mira Bernardo. Él se fue y regresó con una fortuna... Trabajó de camarero y ahora tiene su propio negocio. [...] Pero, tú, cuñadito... Hubo que traerte para que no te murieras de hambre... (Pombero 2004: 14).

Jaime y Paco son personajes antitéticos que representan dos concepciones opuestas; así, Jaime es pragmático mientras Paco es un soñador; Jaime privilegia el Parque del Retiro, mientras Paco ennoblece Central Park: "[...] Cuando llegaba el otoño prefería Central Park. No, no es como el Retiro, querido cuñado. Tu nunca has estado allí ni en ningún otro lugar" (Pombero 2004: 16).

Jaime humilla a Paco y, al mismo tiempo, asume un rol patriarcal con Isabel hasta que esta reacciona y como su madre tomará conciencia de su propia realidad y asumirá que únicamente ella podrá cambiar el rumbo de su vida:

IsABEL. ¡Deja en paz a mi hermano!

JAIME. ¡Ese es exactamente el problema!. ¡Nos hemos pasado la vida protegiéndolo!

Paco. ¡Yo no necesito tu protección, ni la de nadie!

IsABEL. Paco, no le hagas caso.

Jaime. Pues debería hacerme caso. Debería escuchar que alguien le diga la mierda de vida que tiene.

IsABEL. ¡Basta!. Tú no tienes derecho a recordarle a nadie la clase de vida que tiene ¿Por qué no me miras a mí? ¿En que has convertido tu mi vida? ¿En qué clase de mierda?. (Pombero 2004: 47-48).

Esta relación de oposición entre dos personajes se da también entre los dos personajes femeninos. María e Isabel, madre e hija tendrán, también, además de un conflicto generacional que en algún momento se invierte -siendo Isabel la que asume un papel machista en vez de su madre- un conflicto personal. Isabel no se sentirá querida por su madre, en cierto modo, el amor maternal de María murió con Luisa, e Isabel le recriminará su actitud cuando le espeta "eso es lo que has estado haciendo con nosotros toda la vida. Eso, y cortar cualquier manifestación de amor en esta casa" (Pombero 2004: 20-21) o cuando directamente, afirma: "Siento no ser Luisa. Yo solo soy Isabel" (Pombero 2004: 31). Pero esta relación cambiará cuando María revele a su hija qué sucedió el día en que murió su hermana Luisa: 
MAría. Como siempre yo estaba sola [...] Aquella noche había baile en pueblo [...] Los hombres son de otra manera, hija. A ellos no les remuerde tanto la conciencia y se dejan llevar más por sus placeres [...] Luisa lloraba [...] Solo quería acostarme y poder dormir. "Ojalá se calle para siempre”, pensé [...] Cerré dando un portazo, ella se quedó allí sola [...] Me fui a la habitación de Paco [...] La seguí escuchando llorar, pero a mí solo me importaba aquella orquesta, que sonaba a lo lejos [...] Ya sabéis el resto [...]

IsABEL. Lo siento, mamá, perdóname... (Pombero 2004: 80).

Pero, sin duda, como comentaba anteriormente, el detonante de la obra será el conflicto entre el matrimonio conformado por María y José. Cuando José a través de su enfermedad habla libremente, y sin ser consciente del daño que causa su romance de juventud, es cuando conocemos las consecuencias de este y del deterioro de la relación de pareja y cuando comenzamos a entender la vida de "María mujer", no solo la de "María madre":

María. Cuántas cosas se dan siempre por hechas... Cuántas veces nos equivocamos. Esa canción. Esa dichosa canción... Nunca la bailaste conmigo, José. De eso estoy segura. Sin embargo... Sí recuerdo la letra de la canción... Y quién llevaba un vestido azul con unas flores... blancas (Pombero 2004: 62).

Concebimos entonces cómo María se ha transformado en una mujer que jamás imaginó; cómo ella también ha perdido sus sueños sin saber dónde ni cuándo; entendemos cómo se ha consumido su tiempo y su vida en el cuidado de marido e hijos. Ella misma, recrimina a José: "Se acabaron los bailes el día que nos casamos. Se acabaron los paseos el día que nos casamos" (Pombero 2004: 62).

Sin embargo, estas mujeres pueden emprender y rehacer sus vidas porque esta les ofrece una nueva oportunidad que sin duda no van a despreciar. Porque son capaces de atribuir a sus maridos e hijos la responsabilidad moral con respecto a una imposición de vida y, por ende, a la aniquilación de su libertad. Cuando regreses a Nueva York refleja una sociedad que podría insertarse dentro de la corriente compatibilista, que considera posible cierto grado de libertad dentro de una concepción determinista condicionada por unas restricciones sociales marcadas por el patriarcado de antaño que aún cuesta olvidar por permanecer en la memoria colectiva; pero que poco a poco va perdiendo fuerza a través de las nuevas generaciones de mujeres. Por tanto, la obra parte de dos determinismos ya caducos, un determinismo social y un determinismo individual, y nos ofrece el nuevo camino que emprenderán sus protagonistas.

No es el caso de Amina protagonista femenina de la obra epónima. En ella, encontraremos un aplastante determinismo impuesto en distintos niveles, esto es, a nivel social, geográfico, y cultural. Este determinismo estará basado en unas leyes que sin duda favorecen el patriarcado y el sometimiento de la mujer; pero a su vez, encontramos también un determinismo individual, en determinados personajes femeninos, como son la madre de Amina y la segunda esposa, desarrollados estos desde distintas vertientes o en distintos niveles como es el ambiental, educacional, etc. 
Amina es la historia desgarradora ${ }^{4}$ de una joven menor de edad que es violada y obligada a casarse con su violador. La le ley permite al violador el arrepentimiento y esta petición de perdón le ofrece la posibilidad de contraer matrimonio con la víctima. Los pocos recursos económicos de los Nafel familiares de Amina-, junto con una concepción del honor de la familia ante dicho acontecimiento abocarán a Amina a un matrimonio desdichado. Por otro lado, la familia de Mustafá, los Alam, a cambio de limpiar su nombre y el de su hijo, se comprometen al cuidado de Amina, a la que mantendrán bajo su hogar.

Amina rogará a su familia que no la entregue a su violador, pero el poder otorgado al padre hará de su petición una anécdota. A esto, se sumará la concepción social de que una mujer violada pasa a ser una mujer impura por lo que el matrimonio es la única vía que puede purificarla; en definitiva, un camino que la condenará a un matrimonio forzoso y por consecuencia amargo. Únicamente su madre y la segunda esposa del señor Nafel rogarán a este que no permita el matrimonio. Una sociedad patriarcal, la imposibilidad de asumir los acontecimientos que están cambiando su vida bajo el respaldo de la ley la llevarán a un estado de sufrimiento que desembocará en el suicidio.

Se podría decir que Amina es un grito hacia la injusticia del núcleo societal -la familia- que amparaba la justicia marroquí y que Carmen Pombero, por ello, ha querido reflejar fielmente muchos de los sucesos reales del caso que salieron a la luz tras el suicidio de Amina. Aún así, no funciona como un teatro-documento plagado de datos reales, sino todo lo contrarío. Pombero ha conseguido revestirlo de una gran belleza al utilizar dos elementos que creo fundamentales en la estructura de la pieza. Por un lado, la utilización de dos cuentos que enraízan la obra con lo tradicional, y por otro, la utilización de una estructura algebraica, con manipulación del tiempo que es capaz de sumergir al lector en la pesadilla de nuestra protagonista.

Dos narraciones, a modo de intertextos funcionan en la obra como elementos de referencialidad contextual e intertextual. El cuento tradicional africano La palmera y la piedra ${ }^{5}$ y el de Jorge Bucay, La princesa busca marido ${ }^{6}$.

4 Por desgracia este hecho está basado en un acontecimiento real ocurrido en 2012 en Larache, el caso de Amina Filali. Este suceso fue significativo, ya que dos años después el código penal marroquí suprimió el artículo 475 que permitía al violador de una menor eludir la cárcel si contraía matrimonio con ella.

5 La palmera y la piedra, cuenta la historia de una palmera a la que Ben Sadok coloca una enorme piedra en su copa, por haber herido su vista con su belleza. El peso de esta gran piedra impide el crecimiento de la palmera y esta se ve obligada a profundizar su raíces en la tierra, de este modo encuentra unas vetas de agua que la ayudan en su crecimiento e impiden su muerte. Al cabo de unos años, Ben Sadok vuelve al palmeral sin dar crédito a la belleza y fuerza de la palmera.

6 La princesa busca marido, nos narra la condición que pone la princesa a sus pretendientes para optar a ser su esposo: tendrán que aguardar en el muro del palacio sin alejarse ni un solo instante durante 365 días. Tan solo uno de sus pretendientes aguanta hasta el último día pero antes de que este acabe decide marcharse. 
El primero de ellos establece a nivel contextual un paralelismo entre el rol femenino y el masculino, siendo la mujer - la palmera- y el hombre - la piedra-. En consecuencia es la mujer la que debe asimilar y aceptar un destino impuesto para poder sobrevivir o lo que es lo mismo, asumir que serán estas dificultades las que la harán fuerte conllevando este discurso una actitud de sacrificio. De esta forma, será Zaida, en la escena tercera, la encargada de narrar el primero de los cuentos, mientras ella y su corte maquilla a Amina con la tradicional henna. Zaida que podríamos catalogar, o más bien podría decir, que surte un efecto de lo que se denomina como un personaje pseudo-dramaturgo, es el personaje encargado de integrar la narración dentro del drama a modo didáctico, y con ello se procura la inserción de la diégesis en la mímesis evitando con ello la distancia de la función del narrador como tal.

De tal suerte, la pregunta final que Zaida hace a Amina, la realiza, por tanto, también al lector-público: "Zaida. ¿Has entendido la historia que te acabo de contar? [...] Amina. No sé... No estoy muy segura” (Pombero 2013: 33). La contestación de Amina funciona como prefiguración del final del personaje; así, a medida que Amina va entendiendo La palmera y la piedra empieza a descubrir y comprender su destino, y este será el motivo por el que dará el paso de huir, en un intento desesperado de que su padre la acoja de nuevo, pero su destino ya está trazado.

Zaida vuelve a narrar otra historia, La princesa busca marido, pero esta vez el receptor de la historia no es Amina, sino otra novia y de nuevo el lector-público. Con esta segunda intervención del personaje de Zaida, Carmen Pombero nos prepara para el final de Amina. La nueva novia sí entiende la fábula, sí entiende que debe ser amada y respetada y, de este modo, cierra su intervención afirmando: "Novia. La moraleja es que el merecimiento es dignidad, no egolatría... No te merece el esposo que te haga sufrir" (Pombero 2013: 42). El público-lector está ya preparado para la decisión que nuestra protagonista tomará al comprar el veneno con el que se quitará la vida.

Sin embargo, no será hasta el final de la obra cuando se nos descubra su decisión final, de esta forma el suspenso irá en aumento al hacernos pensar que Amina quiere acabar con su marido y su familia:

Amina. ¿Cuál es el más fuerte?

VENDEDOR. El veneno que mata lo que más tememos.

Amina piensa unos segundos y, finalmente, señala unos sobres, los más grandes, de color verde. El vendedor le extiende el matarratas.

$[\ldots]$

Mustafá. ¡Tenemos hambre, mujer!

Señora Alam. ¡Qué niña tan torpe!

SEÑor Alam. Demasiado joven...

$[\ldots]$

Amina está ahora sola, sentada de rodillas a la mesa. Come las verduras que ha dejado macerando mientras canta una cancioncilla infantil. A cada cucharada 
que toma le dan arcadas, pero ella no deja de comer, con lágrimas en los ojos [...] Cuando arrecian con fuerza los dolores, Amina suelta un alarido. Mustafá acude enseguida (Pombero 2013: 46-48).

Igualmente y para acceder al estado anímico de la protagonista, C. Pombero propone un juego con la sucesión de los acontecimientos en la obra. Es por ello que la materia diegética no seguirá el orden lógico y cronológico de los sucesos, proponiéndonos una alteración del mismo a través regresiones $\mathrm{y}$, al igual que en Cuando regreses a Nueva York, también encontraremos escenas en las que se simultanean la espacio-temporalidad.

En seguida observamos la distribución de las doce escenas que conforman la obra, estableciéndose desde la escena primera a la séptima un tiempo regresivo con una alteración del orden lógico y saltos temporales. Así la escena primera y quinta, exponen una regresión a la playa donde Amina fue violada y encontrada, siendo esta última escena la que altera el orden de los acontecimientos, proponiendo un salto al pasado, ya que desde la escena segunda a la cuarta queda expuesto en un orden lógico los acontecimientos que siguen: el acuerdo de boda, la preparación de la novia y el rapto de la novia por los amigos del novio. La inserción en la escena quinta donde se regresa al espacio de la violación funciona como recurso para recrear, para volver a vivir, en definitiva para que el lector-público pueda asistir y vivenciar el conflicto de Amina, ya que para vivir su conflicto se necesita vivir su tiempo, es decir el tiempo de la violación. Con respecto a este hecho, la escena se expone de una forma metonímica, pues el lector no llega a asistir a este acontecimiento sino al abandono de Amina en la playa: " [...] Amina yace en la tierra boca abajo con los labios entre abiertos, cubiertos de polvo y los párpados cerrados, sucia, enmarañada, a medio desvestir" (Pombero 2013: 34).

A este tenor, las escenas sexta y séptima se presentan, también, como regresivas al momento de la boda; en la sexta expresa la denuncia que realiza la familia de Amina y sirve para desarrollar y mostrar el papel de la mujer en la sociedad marroquí, ya que a pesar de que la madre de Amina se opone al matrimonio, su opinión no se tendrá en consideración: "La señora Nafel niega, pero el señor Nafel está tan destrozado anímicamente que no contesta, lo que es tomado como un sí por el jefe de la policía" (Pombero 2013: 38). Igualmente se aprecia el poder otorgado por la ley al hombre al exponerse cómo los familiares de Mustafá recurren a la ley marroquí: “artículo 475 del Código Penal Marroquí [...] permite el agresor o violador casarse con su víctima y evitar así el juicio y la probable pena de cárcel" (Pombero 2013: 38).

La última escena regresiva, correspondiente a la escena séptima, es una de las escenas más duras y, a la vez, más bella de la obra. En ella Amina y su madre, aparecen abrazadas mientras la madre mece a Amina; será esta la que exponga a madre sus miedos, su dolor, su amargura y su rabia ante la injusticia, mientras su madre únicamente le expondrá su obligación, la de callar. La escena culmina con la intervención de la madre en la que le marca el camino de la mujer en su 
sociedad: "Madre. Shhh... Calla, Amina, calla. Nosotras tenemos que callar" (Pombero 2013: 40).

La escena octava nos devuelve a un tiempo que podemos denominar como primario; es el tiempo en el que Amina ya desposada, vive en casa de sus suegros. Escena en la que se simultanea dos espacios y temporalidades: el del trabajo infructuoso de Amina, con el de Zaida que relata el cuento a la nueva novia. Este simultaneo de espacio-tiempo y contenido, como apuntaba anteriormente, llevará al lector al irremediable desenlace.

El trabajo duro y el maltrato que sufre por parte de su marido y de su familia mostrará el desafortunado destino de Amina. A través de la narración del cuento de Zaida, el lector y, por ende, la misma Amina aunque no esté presente, poco a poco irá tomando conciencia de la realidad, y aunque probablemente la respuesta del lector ante los acontecimientos no se acerque, ni por asomo, a la determinación de Amina ante el suicidio, nuestro personaje obligado a elegir entre dos caminos -el de seguir con su desdichada vida tras el rechazo de su familia o continuar con su vida- opta por la muerte.

Las dos obras elegidas de Carmen Pombero reflejan de manera precisa que la falta de derechos de la mujer es un hecho que afecta a todo el género femenino en mayor o menor medida, independientemente del contexto social-político donde se encuentre. Ambas obras potencialmente constatan que la distribución de los papeles femeninos y masculinos a lo largo de la historia siempre han estado en desequilibrio, pues las imágenes que se han creado de la mujer han sido y siguen siendo producto de la imaginación masculina; el hueco que se deja a la mujer es el que el hombre quiere dejar para ella, pocas veces ha sido un lugar conquistado, e incluso cuando lo ha sido, hasta a la propia mujer le ha costado romper ese reflejo de cesión que ha proyectado el hombre.

María e Isabel en Cuando regreses a Nueva York toman conciencia de su libertad perdida y optan por recuperarla; en Amina, sin embargo, y a pesar de que la protagonista femenina es consciente del abuso al que es sometida se le imposibilita el cambio.

Estas dos obras exponen los distintos mecanismos establecidos para el sometimiento de la mujer y son fiel reflejo de dos sociedades distintas, en las que el medio condiciona los personajes con el determinismo más absoluto y a todos los niveles en Amina, por un lado; y por otro, cómo este determinismo educacional sigue siendo un lastre en Cuando regreses a Nueva York.

No deja de ser este trabajo analítico un intento por esclarecer la confrontación dialéctica del individuo con su entorno; en definitiva, de intentar clarificar la confrontación con la sociedad y, más concretamente, el esfuerzo que los personajes femeninos de ambas obras realizan por avanzar y modernizar la sociedad que les rodea. 
Bibliografía

Anderson, B. S. y P. Zinsser, J. P., Historia de las mujeres: una historia propia, Barcelona, Editorial Crítica, volumen II, 1988.

Fijes, E., 1972, Actitudes patriarcales: las mujeres en la sociedad, Madrid, Alianza Editorial.

García Barrientos, J. Luis, 2003, Cómo se comenta una obra de teatro, Madrid, Ed. Síntesis.

García Barrientos, J. Luis, 1991, Drama y tiempo, Madrid, CSID.

Harris, M., 1996, El desarrollo de la teoría antropológica. Historia de las teorías de las culturas, Méjico, Ed. Siglo XXI.

Pavis, P., 1998, Diccionario del teatro. Dramaturgia, estética, semiología, Barcelona, Paidós.

Pombero, C., 2004, Cuando regreses a Nueva York, Granada, Diputación de Granada.

Pombero, C., 2013, Amina, María Jesús Orozco Vera (pr.) Editores, Barcelona, Carena.

Rousseau, J. J., 1979, Emilio o la educación, Barcelona, Editorial Bruguera S.A.

Selden, R., Widdowson, P., Brooker, P., 2003, La teoría literaria contemporánea, Barcelona, Ed. Ariel. 